\title{
The role of temporal variables in inhibition produced through extinction
}

\author{
JAMES C. DENNISTON \\ Appalachian State University, Boone, North Carolina \\ and \\ RALPH R. MILLER \\ State University of New York, Binghamton, New York
}

\begin{abstract}
In two experiments with rats as subjects, the temporal characteristics of inhibition produced through extinction were investigated. Each experiment established two independent signals for unconditioned stimulus presentation, one trace and one delay. Following initial training, either the trace or the delay conditioned stimulus (CS) was massively extinguished. In Experiment 1, a summation test established that an extinguished delay CS (but not a neutral CS) passed a summation test with a delay, but not with a trace, transfer excitor, and an extinguished trace CS (but not a neutral CS) passed a summation test with a trace, but not with a delay, transfer excitor. In Experiment 2, a retardation test showed retarded behavioral control by an extinguished delay CS when the CS was retrained as a delay CS, but not as a trace CS, and by an extinguished trace CS when the CS was retrained as a trace CS, but not as a delay CS. The results are discussed in terms of contemporary theories of extinction.
\end{abstract}

For many years, students of animal learning and behavior have been interested in the processes underlying experimental extinction. As a result of pairings of a conditioned stimulus (CS) with an unconditioned stimulus (US), the CS acquires behavioral control, which is indicative of an excitatory association with the US. Following such training, if the CS is presented in the absence of the US, behavioral control by the CS decreases. The processes responsible for this loss of responding (i.e., experimental extinction) have been debated since the time of Pavlov (1927). Pavlov hypothesized that following CS-US pairings, nonreinforced presentations of the CS result in the formation of inhibitory associations between the CS and the US representation centers in the cortex, which counteract the previously acquired excitatory associations. Importantly, on the basis of his observations of disinhibition, as well as of spontaneous recovery of excitatory responding with a sufficiently long interval between extinction and testing (which

The data reported herein were part of a dissertation submitted by J.C.D. to SUNY-Binghamton in partial fulfillment of the doctor of philosophy degree. J.C.D. thanks his dissertation committee members, Peter Balsam, Ralph Miller, Lisa Savage, and Norman Spear, for their insights and advice relating to this project. Support for this research was provided by National Institute of Mental Health Grant 33881 and by an APA Dissertation Research Award. We thank James Esposito for his technical support and Francisco Arcediano, Aaron Blaisdell, Daniel Burger, Raymond Chang, Daniel Choi, Martha Escobar, John Genua, and Hernan Savastano for comments on an earlier version of this manuscript. Correspondence concerning this article should be addressed to J. C. Denniston, Department of Psychology, Appalachian State University, Boone, NC 28608 (e-mail: dennistonjc@ appstate.edu).

-Accepted by the previous editorial team of Ralph R. Miller. Vincent M. LoLordo was the action editor for this manuscript. he believed to be the result of inhibition's dissipating over time; see, also, Konorski, 1948), Pavlov concluded that extinction did not result in the destruction of the excitatory CS-US association. Despite these findings, more recent models of associative learning (e.g., Rescorla \& Wagner, 1972) have conceptualized experimental extinction as the weakening of the CS-US association (i.e., unlearning; Melton \& Irwin, 1940; but see Postman \& Stark, 1969). However, in recent years, theories of extinction have come full circle back to the views of Pavlov.

In the present series of experiments, the informational content of the inhibitory associations formed during experimental extinction was investigated. Prior research has demonstrated that in a conditioned taste aversion preparation, massive extinction treatment can result in a stimulus that has net inhibitory properties (Calton, Mitchell, \& Schachtman, 1996; Hart, Bourne, \& Schachtman, 1995; Schachtman, Threlkeld, \& Meyer, 2000). Other research in which the role of temporal variables in conditioned inhibition has been investigated has found that following Pavlovian inhibition training (i.e., interspersed $A \rightarrow U S$ and $\mathrm{AX} \rightarrow$ no US presentations), a conditioned inhibitor exerts maximal inhibitory behavioral control at the temporal location at which the US expected during training was omitted (e.g., Barnet \& Miller, 1996; Burger, Denniston, \& Miller, 2001; Denniston, Blaisdell, \& Miller, 1998; Denniston, Cole, \& Miller, 1998). In the present research, we sought to investigate whether massive extinction treatment following Pavlovian fear conditioning could establish a net inhibitor and whether this form of inhibition would be influenced by temporal variables.

Rescorla and Wagner (1972) based their view of extinction as unlearning, in part, on the findings of facilitated reac- 
quisition following extinction (Konorski \& Szwejkowska, $1950,1952)$, as well as on the absence of negative summation of an extinguished CS with a known excitor (LoLordo \& Rescorla, 1966). Thus, there is a literature suggesting that an extinguished CS fails both of the conventional tests for conditioned inhibition (i.e., summation and retardation) proposed by Rescorla (1969; see, also, Hearst, 1972). Although these findings are consistent with the Rescorla-Wagner model, other researchers have found evidence of inhibitory associations in extinction. For example, Pavlov (1927) discussed the possibility of what he called extinction beyond zero. That is, he found that if a conditioned stimulus was extinguished well beyond the point at which responding was no longer observed, hereafter referred to as the zero point, evidence for inhibitory associations could be found. Specifically, following extinction treatment, Pavlov observed that presentations of the US alone could partially restore the conditioned response to the CS. However, if extinction was carried out well beyond the point of no responding, more US-alone presentations were required to restore responding to the CS than would be required if extinction were conducted only until responding was eliminated.

Although excitatory associations below the threshold for supporting responding (i.e., subthreshold) could explain these findings, other studies have challenged this alternative explanation. Tchilingaryan (1963), using dogs as subjects, examined changes in the excitability of the motor area of the cortex during extinction. In his experiment, he found that following prolonged extinction, beyond the point at which responding was no longer observed, only suprathreshold electrical stimulation (considerably above the baseline threshold value) of the motor area in the presence of the CS was able to produce leg movement. These findings suggest that the extinguished CS exerted an inhibitory influence on the motor area of the cortex, which could be counteracted only by stimulation greater than that required to produce the unconditioned response in the absence of the CS; that is, the CS passed a form of summation test for inhibition. Similarly, Sergeyev (1961) found that a CS increased the magnitude of the unconditioned response to a US when the CS immediately preceded the US but that, following prolonged extinction, the extinguished CS reduced the magnitude of the unconditioned response to the US, a finding indicative of the extinguished CS's developing inhibitory attributes.

Although these findings suggest that a CS extinguished below the threshold for responding can become inhibitory, other findings, in addition to those already cited, have called into question the validity of these results. Reberg (1972) assessed the potential of an extinguished CS to summate with a known excitor. He found that an extinguished CS produced positive, rather than negative, summation with an excitatory CS, even when extinction was conducted beyond the point at which responding to the extinguishedCS was eliminated. However, it remains possible that the number of extinction trials in Reberg's study was not sufficient to observe negative summation. Consistent with this view, Hendry (1982) expanded upon Reberg's findings by testing summation of multiple extinguishedCSs. She found that extinguishedCSs produced positive summation but that the magnitude of positive summation decreased as the number of extinction trials increased beyond the point of no responding.In fact, after 120 extinction trials, positive summation was no longer observed. Thus, with sufficiently massive extinction, positive summation seemingly can be eliminated. Notably, these results are consistent with both inhibitory and unlearning accounts of experimental extinction.

As was previously mentioned, Konorski and Szwejkowska (1950, 1952; see also Macrae \& Kehoe, 1999, who included a learning-experienced control group) found that an extinguished CS reacquired behavioral control at a faster rate than that in initial acquisition, a finding inconsistent with an extinguished CS becoming inhibitory and, consequently, being retarded in coming to control behavior during reacquisition. Importantly, Konorski and Szwejkowska did not compare reacquisition of behavioral control by the extinguished CS with acquisition of behavioral control by a novel or neutral stimulus, which currently are two of the controls commonly used for evaluating the rate of reacquisition because they control for stimulusnonspecific effects of training and extinction. In more recent research by Bouton and his colleagues, the conditions under which retarded reacquisition occurs have been investigated. Bouton (1986) found that, following prolonged extinction, the extinguished CS reacquired behavioral control at a slower rate than did a novel CS. Although his results could be explained in terms of decreased attention or associability to the extinguished CS (e.g., Pearce \& Hall, 1980), they are also consistent with the possibility that extinction establishes an inhibitory CS-US association. Bouton and Swartzentruber (1989) further explored this possibility. In their study, they found that an extinguished CS was retarded in reacquisition of behavioral control, relative to a novel stimulus, but not to an equivalently exposed neutral stimulus. The latter finding might be due to decreased attention to the CS or to strong CScontext associations interfering with the acquisition (Wagner, 1981) or expression of the CS-US association (Miller \& Matzel, 1988) - that is, the CS-preexposure effect. Furthermore, Bouton and Swartzentruber found that the retardation of behavioral control was greatest when reacquisition training was given in the extinction context. That is, when reacquisition training was given in a context different from that in which extinction had been given, retardation was reduced relative to subjects that received reacquisition training in the extinction context. Bouton and Swartzentruber interpreted their results as evidence for the memory of extinction interfering with retrieval of the excitatory CS-US association. Most recently, Bouton (1993; see, also, Bouton \& Nelson, 1994) has expanded this position into one more similar to Pavlov's-namely, that extinction produces an inhibitory association (i.e., CS-no US) that interferes with the retrieval of the original CSUS association.

Although Bouton and Swartzentruber's (1989) illuminating results are consistent with the view that extinction results in inhibitory conditioning (see, also, Rescorla \& Fur- 
row, 1977; Wagner, Mazur, Donegan, \& Pfautz, 1980), they tested the extinguished CS only for retarded reacquisition of behavioral control, which is but one of the two tests suggested by Rescorla (1969; see, also, Hearst, 1972) as necessary for certifying the existence of conditioned inhibition. Notably, all of Bouton and Swartzentruber's results, including the observed context specificity, can be explained in terms of latent inhibition or decreased attention to the CS as readily as they can be explained in terms of conditioned inhibition. However, Bouton and Swartzentruber were not centrally interested in inhibition. In contrast, Calton et al. (1996; see also Hart et al., 1995), using a conditioned taste aversion procedure, provided strong evidence that extensive extinction endows a flavor CS with inhibitory properties, as evidenced with both retardation and summation tests for inhibition. Their study was the first to report both negative summation and retardation of behavioral control to an extinguished CS with the same training procedures. Although Calton et al. explained their results in terms of the extinguished CS gaining inhibitory properties, they questioned whether this inhibition was the same as that produced through more traditional forms of inhibition training (e.g., Pavlovian discriminative inhibition training). That is, would an extinguished CS produce inhibitory effects identical to those observed with inhibitors established through the procedure in which $\mathrm{A} \rightarrow \mathrm{US}$ and $\mathrm{AX} \rightarrow$ no US trials are interspersed? Notably, inhibition produced by different procedures is now recognized to differ in certain properties. For example, Friedman, Blaisdell, Escobar, and Miller (1998) found that Pavlovian conditioned inhibition, but not explicitly unpaired inhibition, can by disrupted by pretraining exposure to the putative inhibitory CS in the training context. Along with the findings of Williams and Overmier (1988), who found that backward and discriminative inhibitors, but not differential and explicitly unpaired inhibitory CSs, carry collateral excitation that can mask the inhibitory potential of the CS, these findings suggest that the associative structure of inhibition can vary by training procedure.

In the present series of experiments, we investigated whether inhibition produced through extinction could be obtained in a conditioned lick suppression preparation and, if so, whether this type of inhibition would have characteristics similar to those of more traditional forms of inhibition. One characteristic of Pavlovian inhibitors produced using the $\mathrm{A} \rightarrow \mathrm{US}, \mathrm{AX} \rightarrow$ no US procedure is that they apparently encode the temporal location of the omitted US with respect to CS X (Barnet \& Miller, 1996; Burger et al., 2001; Denniston, Blaisdell, \& Miller, 1998; Denniston, Cole, \& Miller, 1998). For example, Denniston, Cole, and Miller found that a Pavlovian inhibitor produced maximal negative summation (inhibition) when inhibition was assessed on a summation test with a transfer excitor that signaled US presentation at the same temporal location as that at which the inhibitor signaled US omission. When these temporal expectancies for US presentation and US omission were inconsistent(i.e., signaled presentation and omission of the US at different times), less negative summation was observed. These findings were explained in terms of the temporal coding hypothesis (Barnet, Arnold, \& Miller, 1991; Matzel, Held, \& Miller, 1988; Miller \& Barnet, 1993; Savastano \& Miller, 1998), which states that (1) temporal contiguity is both necessary and sufficient for learning to occur; (2) associations not only link events in memory, but also incorporate the temporal relationship between the CS and the US as part of the encoded memory (i.e., subjects form temporal maps that link events in memory [Honig, 1981]), (3) the form and timing of the conditioned response are, in part, determined by these temporal maps, and (4) animals can integrate separate temporal maps when elements with separate temporal maps containing a common element (e.g., a US) are presented together, even when the elements were trained separately (we will elaborate upon this point later). On the basis of these findings, in the present series of experiments, we examined whether extensive extinction treatment can result in conditioned inhibition and, if so, whether inhibitors produced through extinction retain information about the temporal location of the absent US, thereby influencing the expression of inhibition.

\section{EXPERIMENT 1 Summation Tests}

In Experiment 1, a summation test was used for conditioned inhibition with a transfer excitor (D1 or T1) that activated an expectancy of US presentation that was temporally consistent or inconsistent with that activated by the extinguished target CS (D2 or T2). The design of Experiment 1 is depicted in Table 1. Experiment 1 was conducted in two replications. In each replication, all the subjects received training that established two target CSs that had different temporal relationships to the US (Phase 2). CS D2 was trained as a delay CS with no gap between CS termination and US onset, whereas CS T2 was established as a trace CS with a 5-sec gap between CS termination and US onset. All the CSs were $5 \mathrm{sec}$ in duration, and the US was a brief mild footshock. Then (Phase 4) the subjects in Group D received massive extinction of the delay CS D2, whereas the subjects in Group T received massive extinction of the trace CS T2. The only difference between the training provided in Replications 1 and 2 was the addition of a third group of subjects in Replication 2 that received exposure to a previously neutral stimulus (C) during extinction training (Phase 4), rather than massive extinction of CSs D2 or T2. This group was included in order to control for stimulus generalization decrement during subsequent negative summation testing, which might otherwise give the appearance of negative summation (e.g., Aguado, de Brugada, \& Hall, 2001). For the purposes of testing, two transfer excitors with different temporal relationships to the US were established in Phases 1 and 3: CS D1 was trained as a delay CS with no gap between CS termination and US onset, whereas CS T1 was trained as a trace CS with a 5-sec gap between CS termination and US onset. In 
Table 1

Design Summary for Experiment 1: Summation Test

\begin{tabular}{lccccc}
\hline Group & Phase 1 & Phase 2 & Phase 3 & Phase 4 & Test \\
\hline \multicolumn{7}{c}{ Replications 1 and 2 } \\
D & D1-US/T1-US & D2-US/T2-US & D1-US/T1-US & D2-no US & D1, D1D2, T1, or T1D2 \\
T & D1-US/T1-US & D2-US/T2-US & D1-US/T1-US & T2-no US & D1, D1T2, T1, or T1T2 \\
& & \multicolumn{4}{c}{ Replication 2 Only } \\
C & D1-US/T1-US & D2-US/T2-US & D1-US/T1-US & C-no US & D1, D1C, T1, or T1C \\
\hline
\end{tabular}

Note-Group names indicate which stimulus (D2, T2, or C) was massively extinguished during Phase 4. Conditioned stimuli (CSs) D2, T2, and C were counterbalanced audiovisual cues; D1 and T1 were counterbalanced audiovisual cues, which served as transfer excitors on summation tests. CSs D1 and D2 were trained as delay CSs with no gap between CS termination and onset of the footshock unconditioned stimulus (US); CSs T1 and T2 were trained as trace CSs with a 5-sec gap between CS termination and onset of the footshock US. A slash (/) indicates interspersed trials.

Replication 1, the subjects were presented either with a test stimulus consisting of one of the transfer excitors alone (i.e., D1 or T1) or with a simultaneous compound stimulus consisting of a transfer excitor and an extinguished target CS (i.e., D1D2, D1T2, T1D2, or T1T2). In Replication 2, the subjects were presented either with a test stimulus consisting of one of the transfer excitors alone (i.e., D1 or T1) or with a simultaneous compound stimulus consisting of a transfer excitor and an extinguished target CS (i.e., D1D2, D1T2, T1D2, or T1T2) or a transfer excitor and the previously exposed neutral stimulus (i.e., D1C or T1C). On the basis of Calton et al.'s (1996) findings, in conjunction with those of Denniston, Blaisdell, and Miller (1998), and Denniston, Cole, and Miller (1998), we expected to observe maximal negative summation in the subjects tested with a transfer excitor and extinguishedCS that signaled US occurrence and US omission, respectively, at the same temporal locations (e.g., testing with a delay transfer excitor and an extinguished delay CS). When these stimuli provided inconsistent temporal expectancies (e.g., testing with a delay transfer excitor and an extinguished trace CS) or when testing was conducted with a transfer excitor and the neutral Stimulus $\mathrm{C}$, negative summation was expected to be reduced.

Method
Subjects
The subjects were 60 male and 60 female experimentally naive
Sprague Dawley rats from our own breeding colony. Body weights
ranged from 243 to $420 \mathrm{~g}$ for the males and from 185 to $315 \mathrm{~g}$ for
the females. The animals were individually housed in standard hang-
ing stainless steel wire-mesh cages in a vivarium maintained on a
16:8-h light:dark cycle. All training occurred approximately mid-
way through the light portion of the cycle. The subjects were allowed
free access to food in their home cages, whereas access to water was
gradually decreased to 10 min per day prior to the initiation of the
experiment. All the subjects were handled for 30 sec three times per
week from weaning until the initiation of the study. In Replication 1 ,
the subjects were randomly assigned to one of two groups ( $n \mathrm{~s}=24)$,
counterbalanced for sex, whereas in Replication 2 , the subjects were
randomly assigned to one of three groups ( $n \mathrm{~s}=24$ ), counterbal-
anced for sex.

\section{Apparatus}

For pragmatic reasons, two types of experimental chambers, designated $\mathrm{R}$ and $\mathrm{V}$, were used. Chamber $\mathrm{R}$ was rectangular in shape and measured $22.75 \times 8.25 \times 13.0 \mathrm{~cm}(1 \times \mathrm{w} \times \mathrm{h})$. The walls and ceiling of the chamber were constructed of clear Plexiglas, and the floor consisted of stainless steel rods measuring $0.48 \mathrm{~cm}$ in diameter, spaced $1.5 \mathrm{~cm}$ center to center. The rods were connected by NE2 neon bulbs, which allowed for the delivery of constant-current footshock produced by a high-voltage AC circuit in series with a 1-m $\Omega$ resistor. Each of six copies of Chamber $\mathrm{R}$ was housed in a separate sound- and light-attenuating environmental enclosure. Chamber $\mathrm{R}$ was dimly illuminated by a $2-\mathrm{W}$ (nominal at 120 VAC) houselight driven at $60 \mathrm{VAC}$. The bulb was located on the inside wall of the environmental enclosure, approximately $30 \mathrm{~cm}$ from the center of the experimental chamber.

Chamber V was a $25.5-\mathrm{cm}$-long box in the shape of a vertical truncated-V. The chamber was $28 \mathrm{~cm}$ high, $21 \mathrm{~cm}$ wide at the top, and narrowed to $5.25 \mathrm{~cm}$ wide at the bottom. The ceiling was constructed of clear Plexiglas, the front and back end walls were black Plexiglas, and the side walls were stainless steel. The floor consisted of two $25.5-\mathrm{cm}$-long parallel stainless steel plates, each $2 \mathrm{~cm}$ wide and separated by a $1.25-\mathrm{cm}$ gap. A constant-current footshock could be delivered through the metal walls and floor of the chamber. Each of six copies of Chamber V was housed in a separate sound- and light-attenuating enclosure. Chamber V was illuminated by a 7-W (nominal at $120 \mathrm{VAC}$ ) bulb driven at $60 \mathrm{VAC}$. The bulb was mounted on the inside wall of the environmental enclosure, approximately $30 \mathrm{~cm}$ from the center of the experimental chamber, with the light entering the chamber primarily by reflection from the ceiling of the environmental enclosure. The light intensities in Chambers $\mathrm{R}$ and $\mathrm{V}$ were approximately equal, despite the discrepancy in the wattage of the light bulbs used, because of differences between the chambers in the opaqueness of the walls.

Chambers $\mathrm{R}$ and $\mathrm{V}$ could each be equipped with a water-filled lick tube. When inserted, the lick tube extended $1 \mathrm{~cm}$ into a cylindrical drinking recess that was set into one of the Plexiglas end walls of the chamber. Each drinking recess was left-right centered, with its bottom $1.75 \mathrm{~cm}$ above the floor of the chamber. The recess was $4.5 \mathrm{~cm}$ in diameter and $5 \mathrm{~cm}$ deep. An infrared photobeam was projected horizontally across the recess, $1 \mathrm{~cm}$ in front of the lick tube. To drink from the lick tube, a subject had to insert its head into the recess, thereby breaking the photobeam. By this means, we could monitor when the subjects were accessing the lick tube. Three speakers, mounted on separate walls in each enclosure, could deliver the following auditory cues: a $6 / \mathrm{sec}$ click train, a white noise, and a low-frequency tone (compound of 300 and $320 \mathrm{~Hz}$ ), each $8 \mathrm{~dB}(\mathrm{C})$ above the ambient background of $74 \mathrm{~dB}(\mathrm{C})$, re. SPL, which was produced primarily from a ventilation fan on each environmental enclosure. Each speaker delivered one of the three auditory stimuli. In addition, a buzzer could also produce a buzz stimulus approximately $8 \mathrm{~dB}(\mathrm{C})$ above the ambient background. Each chamber could also provide a flashing-light stimulus ( $0.17 \mathrm{sec}$ on/0.17 $\mathrm{sec}$ off $)$. In Chamber R, the flashing light was provided by a $25-\mathrm{W}$ bulb (nominal at $120 \mathrm{VAC}$ ) driven at $60 \mathrm{VAC}$, whereas the flashing light in Chamber V was provided by a $100-\mathrm{W}$ bulb (nominal at 120 VAC) 
driven at $60 \mathrm{VAC}$. The bulbs were located on the back wall of each environmental chest. Because of differences in the opaqueness of the chamber walls, these two stimuli produced approximately equal illumination in the R and the V chambers. All the CSs were $5 \mathrm{sec}$ in duration, and the US was a $0.5-\mathrm{sec}, 1.3-\mathrm{mA}$ footshock. Chamber type $(\mathrm{R}$ and $\mathrm{V}$ ) was counterbalanced within groups and test conditions.

\section{Procedure}

The experiment was conducted in two replications, each composed of five phases (see Table 1). The only difference between Replications 1 and 2 was Phase 4 treatment and testing. In Phases 1 and 3 , all the subjects received transfer excitor training, which established two independent signals for US presentation that would subsequently be used during summation testing for inhibition. CS D1 was trained as a delay excitor with no gap between the CS and the US, whereas CS T1 was trained as a trace excitor with a 5-sec gap between the CS and US. The rationale for providing transfer excitor training both before and after training of CSs D2 and T2 was to avoid long retention intervals both between target CS extinction and testing and between transfer excitor training and testing. Phase 2 of the experiment established stimuli D2 and T2 as CSs. CS D2 was trained as a delay CS, whereas CS T2 was trained as a trace CS. In Phase 4, the subjects in Replication 1 received extinction of either CS D2 (Group D) or T2 (Group T), whereas the subjects in Replication 2 received extinction of CS D2 (Group D), extinction of CS T2 (Group T), or equivalent exposure to a previously novel CS, C (Group C). Finally, in the test phase, conditioned inhibition was assessed by means of a summation test, in which the potential of D2 and T2 (Replication 1) or D2, T2, and C (Replication 2) to reduce responding to the transfer excitors (D1 and T1) was observed.

Acclimation. Acclimation to the experimental chambers was conducted on Day 1 during a single 60-min session. Water-filled lick tubes were available, and no nominal punctate stimuli were presented. This phase of the experiment served to establish a stable baseline level of drinking behavior, a departure from which would serve as the dependent variable during testing. Following acclimation, the water-filled lick tubes were removed from all the chambers.

Transfer excitor training (Phase 1). The first phase of transfer excitor training was conducted during daily 60-min sessions on Days 2 and 3. For all the subjects, CSs D1 and T1 were the buzz or the click train, counterbalanced within each test condition for each group. During each session, four reinforced D1 trials and four reinforced T1 trials were given interspersed. CS D1 was trained as a delay CS, with no gap between CS termination and US onset. CS T1 was trained as a trace CS, with a 5-sec gap between CS termination and US onset. The trial order was D1, T1, T1, D1, T1, D1, D1, T1. The mean intertrial interval (ITI) for the eight trials was $7 \mathrm{~min}$ (range, 4-10 $\mathrm{min}$ ).

Target excitor training (Phase 2). All the subjects received target excitor training during four daily 60-min sessions (Days 4-7). During each of these sessions, the subjects received four reinforced presentations of each of D2 and T2. CS D2 was trained as a delay CS with no gap between CS termination and US onset, and CS T2 was trained as a trace CS with a 5-sec gap between CS termination and US onset. For all the subjects, D2 and T2 were the low-frequency tone, the flashing light, or the white noise, counterbalanced within test condition (see Table 1) for each group. (Three different stimuli, rather than two, served as CSs D2 and T2 in Replication 1 in order to maintain full counterbalancing with neutral Stimulus C in Replication 2 and equivalency with Experiment 2, which for reasons that will be explained later, used a Target Stimulus $\mathrm{C}$ in addition to D2 and T2.) The mean ITI was the same as that in transfer excitor training. The trial order was T2, D2, D2, T2, D2, T2, T2, D2.

Transfer excitor training (Phase 3). The second half of transfer excitor training (Days 8 and 9) was identical to that given in Phase 1.

Extinction (Phase 4). Following transfer excitor training, the subjects received extinction of either CS D2 or T2 over five daily 60min sessions (Days 10-14). The subjects in Group D received a total of 1,000 extinction trials of D2, whereas the subjects in Group T received 1,000 extinction trials of T2. Group C in Replication 2 received massive nonreinforced exposure to Stimulus C (a previously novel stimulus). All the subjects received 200 extinction trials of their designated CS per session. The mean ITI was $18 \mathrm{sec}$ (range, $10-26 \mathrm{sec}$ ).

Reacclimation. The lick tubes were returned to the chambers. All the subjects were then reacclimated to the experimental context during two 60-min daily sessions (Days 15 and 16). These sessions served to stabilize baseline drinking following the disruption produced by the footshock USs.

Testing. Negative summation testing occurred during a single test session (Day 17). The subjects in Group D were randomly assigned to one of four test conditions (D1, D1D2, T1, and T1D2; $n \mathrm{~s}=6$ per replication). Similarly, the subjects in Group $\mathrm{T}$ were randomly assigned to one of four test conditions (D1, D1T2, T1, and T1T2; $n \mathrm{~s}=$ 6 per replication). The subjects in Group C of Replication 2 were randomly assigned to one of four test conditions (D1, D1C, T1, and $\mathrm{T} 1 \mathrm{C} ; n \mathrm{~s}=6$ per subgroup). On the test day, the animals were allowed to drink from the lick tubes for five cumulative seconds, after which the test stimuli were presented. Thus, all the subjects were drinking at the moment of test stimuli onset. The time to complete an additional five cumulative seconds of licking in the presence of the test stimuli was recorded. A 10-min ceiling was imposed on the suppression scores. The subjects that were tested on compound test stimuli (e.g., D1D2) received simultaneous stimulus presentations.

Data analysis. Prior to statistical analysis, all the suppression scores were converted to $\log$ (base 10) scores in order to better normalize the within-group distributions, thereby allowing the use of parametric statistics. An alpha level of .05 was adopted for all the statistical tests. Any subject taking more than $60 \mathrm{sec}$ to complete its first five cumulative seconds of drinking (prior to CS onset) on the test day, thus exhibiting a great reluctance to drink in the test context, was scheduled to be eliminated from the data analysis. In practice, 3 subjects from Replication 2-2 from Group T that were tested on D1T2 and 1 from Group C that was tested on T1-met this criterion.

\section{Results and Discussion}

The central findings from this study were that less conditioned suppression (i.e., more behavior indicative of conditioned inhibition) was observed in the subjects that were tested with the D1D2 compound, relative to D1 alone, and with the T1T2 compound, relative to T1 alone (see Figure 1). Importantly, the associatively neutral Stimulus $\mathrm{C}$ failed to produce substantial negative summation. In addition, inhibitory behavioral control was somewhat attenuated when testing was conducted with D1T2, relative to D1 alone, and with T1D2, relative to T1 alone. Thus, maximal conditioned inhibition was observed when testing was conducted with an extinguished excitor that had previously signaled US presentation at the same temporal location as that at which the transfer excitor signaled US presentation. When these temporal expectancies were inconsistent, conditioned inhibition was reduced. The findings above were confirmed with the following statistical analyses.

Prior to analysis of group differences in suppression to the test stimuli, we first analyzed the effects of replication and group-test-stimulus on the suppression scores obtained over the two replications, thereby providing justification for the pooling of data over replications. A $2 \times 8$ analysis of variance (ANOVA), with replication (1 or 2) and group-test-stimulus (D-D1, D-D1D2, D-T1, DT1D2, T-D1, T-D1T2, T-T1, or T-T1T2) as factors, was 


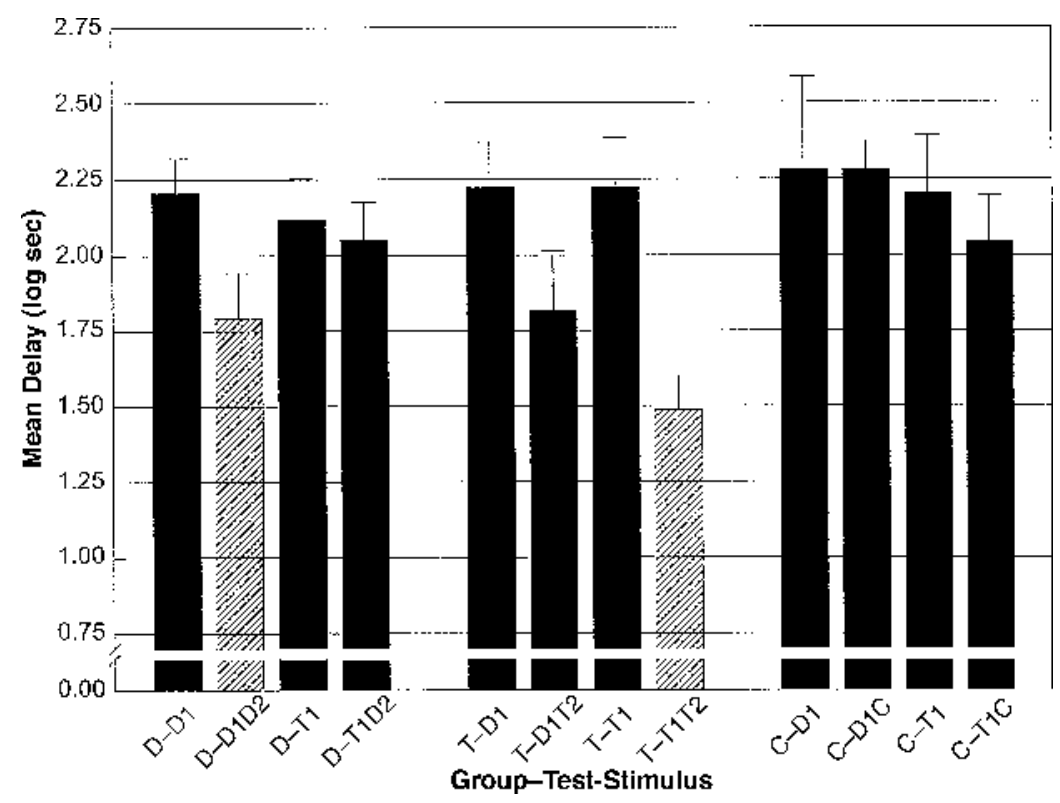

Figure 1. Experiment 1: summation test with Transfer Excitors D1 and T1. Treatment identification refers to group (which stimulus was extinguished during Phase 4) and stimulus presented at test. Bars depict mean times to complete five cumulative seconds of drinking in the presence of the test stimuli. Error brackets denote the standard errors of the mean. Striped bars indicate groups in which maximal inhibition was expected. Higher scores indicate less conditioned inhibition. See Table 1 for procedural details.

conducted on the suppression scores in the presence of the test stimulus in each replication. This analysis excluded data from the subjects in Group C (Replication 2), because this control group was not included in Replication 1. The ANOVA revealed a main effect of replication $[F(1,78)=$ $4.16, p<.05]$ and a main effect of group-test-stimulus $[F(7,78)=3.45, p<.01]$ but, importantly, no interaction $(F<1)$. Given the lack of a significant interaction of replication with group-test-stimulus, we pooled the data over replications in all the subsequent analyses. However, given the significant main effect of replication, we avoided comparison of the data from Group C (Replication2) with any data from Replication 1 . Thus, the data from Group $\mathrm{C}$ were analyzed separately.

Analysis of the times to complete five cumulative seconds of drinking prior to the presentation of the test CS (i.e., pre-CS scores) was accomplished with two separate analyses, one for Groups D and T (pooled over replications) and one for Group C (Replication 2). In these analyses, we sought differential baseline drinking behavior prior to test stimulus presentation in the subjects from each of the data sets described above. Analysis of the baseline drinking scores from Groups $\mathrm{D}$ (Test Conditions D1, D1D2, T1, and T1D2) and T (Test Conditions D1, D1T2, T1, and T1T2) was accomplished with a $2 \times 2 \times 2$ ANOVA, with group (D or T), excitor (D1 or T1), and inhibitor (present or absent) as factors. This analysis revealed no main effects or interactions [all $F_{\mathrm{s}}(1,86)<$
3.10, all $p \mathrm{~s}>.08$ ]. Analysis of the baseline drinking scores from Group C (Test Conditions D1, D1C, T1, and T1C) was accomplished with a $2 \times 2$ ANOVA, with excitor (D1 or T1) and inhibitor (absent or present) as factors. This analysis revealed no main effects or interactions (all $\left.F_{\mathrm{s}}<1\right)$. Thus, there were no significant differences in baseline performance at the time of testing within either of the sets of data.

Analysis of the suppression scores in the presence of the test CS was accomplished with two separate ANOVAs. We first analyzed the suppression scores from the subjects in Groups D (Test Conditions D1, D1D2, T1, and T1D2) and T (Test Conditions D1, D1T2, T1, and T1T2) with a $2 \times 2 \times 2$ ANOVA, with group (D or T), excitor (D1 or T1), and inhibitor (present or absent) as factors. This analysis revealed only a main effect of inhibitor $[F(1,86)=$ $15.71, p<.001$; all other $F_{\mathrm{s}}<2.60$, all $\left.p \mathrm{~s}>.11\right]$. Planned comparisons using the error term from the overall ANOVA were conducted on the suppression scores from Group D. This revealed less suppression to D1D2 than to D1 alone $[F(1,86)=4.16, p<.05]$, indicative of CS D2 passing a summation test for conditioned inhibition with Transfer Excitor D1, whereas there was no difference in suppression between T1 and T1D2 $(F<1)$, indicative of CS D2 failing to pass a summation test for conditioned inhibition with Transfer Excitor T1. Comparison of suppression scores from Group $\mathrm{T}$ revealed less suppression to $\mathrm{T} 1 \mathrm{~T} 2$ than to $\mathrm{T} 1$ alone $[F(1,86)=13.25, p<.001]$, and 
somewhat less suppression to D1T2 than to D1 alone $[F(1,86)=3.66, p>.05]$, indicative of CS T2 passing a summation test for conditioned inhibition with Transfer Excitor T1, but not with Transfer Excitor D1. Notably, CS T2 produced some attenuation of responding when compounded with Transfer Excitor D1, a result that suggests that inhibition is not fully dependent on a match between the temporal relationship of the inhibitor to the omitted US and the temporal relationship of the transfer excitor to the US. Additional comparisons revealed that although there was no difference in suppression between D1D2 and D1T2 $(F<1)$, there was less suppression to T1T2 than to T1D2 $[F(1,86)=7.81, p<.01]$, suggesting that CS T2 was a more effective inhibitor of CS T1 than was CS D2.

A $2 \times 2$ ANOVA, with excitor (D1 or T1) and inhibitor (absent or present) as factors, was conducted on the suppression scores from Group C (Test Conditions D1, D1C, T1, and T1C) of Replication 2. This analysis revealed no main effects or interactions (all $F \mathrm{~s}<1$ ). Planned comparisons failed to reveal differences between D1 and D1C and between $\mathrm{T} 1$ and $\mathrm{T} 1 \mathrm{C}$ (all $F_{\mathrm{s}}<1$ ). These analyses suggest that the attenuation of responding reported in the prior analyses was not the result merely of stimulus generalization decrement.

Thus, Experiment 1 showed that a massively extinguished conditioned excitor was capable of passing a summation test for conditioned inhibition, a result that replicated, in a conditioned lick suppression preparation, the findings reported by Calton et al. (1996) in a conditioned taste aversion preparation. In addition, these results demonstrated that inhibition produced through extinction can, in some cases, display the same temporal specificity as conditioned inhibitors established through Pavlovian discriminative conditioned inhibition training (e.g., A $\rightarrow$ US/ AX $\rightarrow$ no US; Barnet \& Miller, 1996; Burger et al., 2001; Denniston, Blaisdell, \& Miller, 1998; Denniston, Cole, \& Miller, 1998). That is, in the present experiment, a massively extinguished delay CS (D2), but not a massively extinguished trace CS (T2) or an equivalently exposed (during extinction) stimulus (C), inhibited responding to a delay transfer CS (D1). Similarly, a massively extinguished trace CS (T2), but not a massively extinguished delay CS (D2) or an equivalently exposed neutral stimulus (C), inhibited responding to a trace transfer CS (T1). Importantly, the negative summation produced by the extinguished CS was not merely the result of stimulus generalization decrement. That is, the equivalently exposed neutral CS C failed to attenuate conditioned responding to either transfer CS.

One unanticipated finding was that the extinguished Trace CS T2 not only produced robust inhibition when compounded with trace Transfer CS T1 (as was expected), but also produced substantial (albeit nonsignificant) inhibition when compounded with delay Transfer CS D1. This finding is inconsistent with strict temporal specificity of inhibition, which was observed in Group D, in which the extinguished delay CS D2 produced reliable inhibition when compounded with delay Transfer CS D1, but not with trace Transfer CS T1. This result suggests either that the extinguished trace CS was a more effective inhibitor regardless of transfer excitor-US temporal relationship or, more likely, that the temporal control of inhibition produced through extinction is not an all-or-none phenomenon. That is, the extinguished delay CS produced modest (reliable) inhibition when compounded with the delay transfer CS and somewhat less inhibition when compounded with the trace transfer $\operatorname{CS}[F(1,86)=1.62, p<$ .21]. Similarly, the extinguished trace CS produced robust inhibition when compounded with the trace transfer CS and somewhat less inhibition when compounded with the delay transfer CS $[F(1,86)=2.45, p<.13]$. Although these differences were not statistically reliable, the numerical differences were in the direction suggestive of inhibition's waning when there is a temporal mismatch between the temporal expectancy for US omission signaled by the extinguished excitor and the temporal expectancy for US presentation signaled by the transfer excitor.

\section{EXPERIMENT 2 Retardation Tests}

Experiment 1 showed that a massively extinguishedexcitor could pass a summation test for conditioned inhibition and that the greatest inhibition was observed when the extinguished CS signaled omission of the US at the same temporal location as that at which the transfer excitor signaled US presentation. Importantly, this attenuation of responding was not merely the result of stimulus gen-

Table 2

Design Summary for Experiment 2: Retardation Test

\begin{tabular}{lllllll}
\hline Group & Phase 1 & \multicolumn{1}{c}{ Phase 2 } & Phase 3 & Phase 4 & Phase 5 & Test \\
\hline D-Delay & D1-US/T1-US & D2-US/T2-US & D1-US/T1-US & D2-no US & D2-Delay-US & D2 \\
T-Delay & D1-US/T1-US & D2-US/T2-US & D1-US/T1-US & T2-no US & T2-Delay-US & T2 \\
C-Delay & D1-US/T1-US & D2-US/T2-US & D1-US/T1-US & D2-no US & C-Delay-US & C \\
D-Trace & D1-US/T1-US & D2-US/T2-US & D1-US/T1-US & D2-no US & D2-Trace-US & D2 \\
T-Trace & D1-US/T1-US & D2-US/T2-US & D1-US/T1-US & T2-no US & T2-Trace-US & T2 \\
C-Trace & D1-US/T1-US & D2-US/T2-US & D1-US/T1-US & T2-no US & C-Trace-US & C \\
\hline
\end{tabular}

Note-Group names indicate which target conditioned stimulus (CS; D2, T2, or C) was paired with the footshock unconditioned stimulus (US) during Phase 5 and the temporal relationship between this CS and the US (delay or trace). CSs D2, T2, and C were counterbalanced audiovisual cues; D1 and T1 were counterbalanced audiovisual cues, which were required in Experiment 1 and were included here only to provide identical training in Phases 1-3 with the prior study. In Phase 4, the subjects received massive extinction of D2 or T2. A slash (/) indicates interspersed trials. 
eralization decrement. Recently, Burger et al. (2001) found that retardation of behavioral control by a conventional Pavlovian conditioned inhibitor (i.e., $\mathrm{A} \rightarrow \mathrm{US}, \mathrm{AX} \rightarrow$ no US training) was greatest when the inhibitor was retrained with the US at the same temporal location as that at which the inhibitor's training excitor had been paired with the US. A mismatch in temporal relationships attenuated inhibitory behavioral control. The present Experiment 2 was designed to investigate whether a massively extinguished CS could pass a retardation test for inhibition and, if so, whether inhibitory behavioral control by the extinguished CS might display temporal specificity.

The design of Experiment 2 (see Table 2) was similar to that of Experiment 1, except for testing for retardation in (reacquiring) stimulus control (instead of a summation test). Following extinction treatment, the subjects received pairings of the extinguished delay or trace CS with the US, in either a delay or a trace temporal relationship with the US. In order to (partially) compensate for potential differences in behavioral control supported by delay and trace CS-US pairings (such as we have observed in pilot studies), during Phase 5, the subjects received either three delay CS-US pairings (in the delay groups) or four trace CS-US pairings (in the trace groups). Since these pairings were known from pilot studies to disrupt baseline drinking, testing occurred following posttreatment reestablishment of baseline drinking. At test, conditioned suppression to the CS trained during retardation training was assessed. We expected that retardation test pairings during Phase 5, which maintained the same temporal relationship with the US as had been established during original acquisition in Phase 2, would lead to the greatest retardation of behavioral control at test (Groups D-Delay and TTrace). In contrast, a change in the CS-US temporal relationship between Phases 2 and 5 was expected to reduce retardation of behavioral control by the test CS (Groups D-Trace and T-Delay). Conditioned suppression to the retrained CS was compared with that for the subjects that received training with a neutral CS during Phase 5 (i.e., Groups C-Delay and C-Trace). Specifically, the levels of suppression to D2 and T2 following delay retardation pairings were compared with those for the subjects that received delay C-US pairings, whereas suppression to D2 and $\mathrm{T} 2$ following trace retardation training was compared with that for the subjects that received trace C-US pairings.

One potential problem with the design of Experiment 2 was the use of different CS-US temporal relationships in Phase 5 (delay or trace), which might result in greater levels of contextual fear in the trace groups than in the delay groups, because the context alone was present immediately prior to the US for the former, but not for the latter, groups. Any effect of differential contextual fear should be evident in differences in baseline drinking rates between Groups C-Delay and C-Trace, in which the subjects received either delay or trace C-US pairings, respectively. Despite the possibility of differential contextual fear, such an effect should not undermine the conclusions that might be drawn from the results of this study, pro- vided that the expected interaction of group (D or T) and CS-US temporal relationship (delay or trace) was observed. That is, we expected retarded acquisition of behavioral control to CS D2 following delay, but not trace, CS-US pairings and to CS T2 following trace, but not delay, CS-US pairings. If the Phase 5 trace CS-US pairings produced greater contextual fear than did the delay CS-US pairings, summation of fear to the context and to the CS presented at test should make it more difficult to observe inhibition of fear in Group T-Trace (which received trace T2-US pairings), which would be contrary to the expected outcome.

\section{Method}

\section{Subjects and Apparatus}

The subjects were 36 male and 36 female 80 - to 120-day-old naive Sprague-Dawley-descended rats from our own breeding colony. The range of body weights for the males was $325-485 \mathrm{~g}$, and for the females it was $215-310 \mathrm{~g}$. Animal care and deprivation were the same as in Experiment 1. The subjects were randomly assigned to six groups $(n \mathrm{~s}=12)$, counterbalanced for sex.

\section{Procedure}

The design and procedure of Experiment 2 were the same as in Experiment 1, with the exception of retardation training, which occurred just prior to reacclimation and testing (see Table 2). The lowfrequency tone, flashing light, and white noise served as CSs D2, $\mathrm{T} 2$, and $\mathrm{C}$, counterbalanced within each group, and the buzz and click train served as CSs D1 and T1, counterbalanced within each group. Training with $\mathrm{C} 1$ and $\mathrm{T} 1$ (Phases 1 and 3) was not central to Experiment 2 but was included in order to maximize similarity between Experiments 1 and 2. Groups D-Delay and D-Trace received massive nonreinforced (extinction) exposure to CS D2, identical to that provided to Group D in Experiment 1, whereas Groups T-Delay and T-Trace received massive nonreinforced exposure to CS T2, identical to that provided to Group $\mathrm{T}$ in Experiment 1. In addition, Group C-Delay received nonreinforced exposure to CS D2, whereas Group C-Trace received nonreinforced exposure to CS T2.

Retardation training (Phase 5). The subjects received delay or trace retardation training with CS D2, CS T2, or a neutral cue (C) during Phase 5 (Day 16). The subjects in Group D-Delay, which had received extinction of Delay CS D2, were provided with three delay D2-US pairings, whereas the subjects in Group T-Delay, which had received extinction of Trace CS T2, were provided with three delay T2-US pairings. The subjects in Group C-Delay, which had received extinction of Delay CS D2, were provided with analogous training with CS C (i.e., three delay C-US pairings) in order to provide a baseline level of performance following three delay conditioning trials; thus, any reduction from this baseline could be viewed as evidence of retardation of acquisition of behavioral control. The subjects in Group D-Trace, which had received extinction of Delay CS D2, were provided with four trace D2-US pairings, whereas the subjects in Group T-Trace, which had received extinction of Trace CS T2, were provided with four trace T2-US pairings. The subjects in Group C-Trace, which had received extinction of Trace CS T2, were provided with analogous training (i.e., four trace C-US pairings) with CS C, in order to provide a baseline level of responding following four trace conditioning trials. These trials were presented at 13,30 , and 48 min into the 60-min session for groups receiving the three delay CS-US pairings and at 10, 23, 37, and 48 min into the 60-min session for groups receiving the four trace CS-US pairings.

The difference in number of retardation pairings between the subjects trained with the delay or the trace temporal relationship in Phase 5 was intended to ensure observable behavioral control in the trace groups, while preventing a ceiling effect in the delay groups 
(which was not a concern in Phases 1 and 3 of Experiment 1, in which we had intended to produce strong responding to both stimuli by providing many CS-US pairings). Importantly, the subjects in Groups C-Delay and C-Trace differed in which stimulus had been extinguished in Phase 4 (CS D2 or T2). This difference resulted in a confound between Groups C-Delay and T-Delay and between Groups C-Trace and D-Trace, because the control and the experimental groups differed not only in terms of which stimulus was trained during Phase 5, but also in terms of which stimulus was extinguished during Phase 4 (D2 or T2). The reason for introducing this confound was that we felt that it was important to provide the control subjects in Groups C-Delay and C-Trace with extinction experience, even at the cost of not equating which stimulus was extinguished. That is, we decided that the treatment provided, with its resulting confound, was a minor confound relative to the omission of extinction experience in the C-Delay and C-Trace groups. Ideally, two additional control groups might have been trained, one with delay $\mathrm{C}$-US pairings following extinction of $\mathrm{T} 2$ and the other with trace C-US pairings following extinction of D2. However, it seemed implausible that extinction of either CS D2 or T2 could appreciably influence acquisition of behavioral control by Stimulus $C$ in Groups $\mathrm{C}-$ Delay and C-Trace, especially given the physical counterbalancing of stimuli serving as CSs D2, T2, and C.

Testing. The testing procedure was similar to that used in Experiment 1 , with the following exception. Testing was conducted with only the CS that was paired with the US during Phase 5 retardation training. The subjects in Groups D-Delay and D-Trace were tested for conditioned suppression to CS D2, the subjects in Groups $\mathrm{T}$-Delay and T-Trace were tested for conditioned suppression to CS $\mathrm{T} 2$, and the subjects in the two control conditions, Groups C-Delay and C-Trace, were tested for conditioned suppression to CS C. At test, the time to complete five cumulative seconds of drinking in the presence of the test CS was recorded.

Data analysis. As in Experiment 1, any subject requiring more than $60 \mathrm{sec}$ to complete the initial five cumulative seconds of drinking prior to test stimulus onset was eliminated from the data analysis. Two animals met this criterion- 1 from Group T-Delay and 1 from Group C-Delay.

\section{Results and Discussion}

The central findings from this study were that, indicative of conditioned inhibition, less conditioned suppression was observed in Groups D-Delay and T-Trace, relative to their respective controls (C-Delay and C-Trace). Conversely, greater conditioned suppression (i.e., behavior indicative of less conditioned inhibition) was observed in Groups D-Trace and T-Delay, which did not significantly differ from their respective controls (C-Trace and $\mathrm{C}-$ Delay). This pattern of results indicates that retardation of behavioral control by an extinguished CS was greatest when the same CS-US temporal interval prevailed during the CS-US retardation test pairings as had prevailed during the initial excitatory training (see Figure 2). These findings were confirmed with the following statistical analyses.

Analysis of the times to complete five cumulative seconds of drinking prior to test stimulus onset was accomplished with a $3 \times 2$ ANOVA, with stimulus (D2, T2, or C) and temporal interval (delay or trace in Phase 5) as factors. This analysis found no main effects of stimulus $(F<1)$, or temporal interval $(F<1)$ and no interaction $[F(2,64)=$ $1.22, p>.30]$. In addition, there was no significant difference in baseline levels of responding between the control groups that received delay and trace $\mathrm{C}-\mathrm{US}$ pairings
$(F<1)$, suggesting that the delay and the trace retardation pairings did not produce differential contextual fear.

An analogous $3 \times 2$ ANOVA, with stimulus and temporal interval as factors, was conducted on the times to complete five cumulative seconds of drinking in the presence of the test stimulus. This analysis revealed a main effect of stimulus $[F(2,64)=9.90, p<.001]$, no effect of temporal interval $[F(1,64)=3.36, p>.05]$, and an interaction of stimulus and temporal interval $[F(2,64)=20.72, p<.001]$.

Planned comparisons in which the error term from the latter $3 \times 2$ ANOVA was used were conducted to identify the source of the interaction. The first set of planned comparisons contrasted the levels of responding in the animals that received delay conditioning of $\mathrm{D} 2, \mathrm{~T} 2$, or $\mathrm{C}$ during retardation training (i.e., Phase 5). These comparisons revealed that the animals in Group D-Delay suppressed less than did the animals in Group C-Delay $[F(1,64)=8.78$, $p<.01]$, whereas there was no difference in suppression between the animals in Groups T-Delay and C-Delay $(F<1)$. In addition, the animals in Group D-Delay suppressed less than did the animals in Group T-Delay

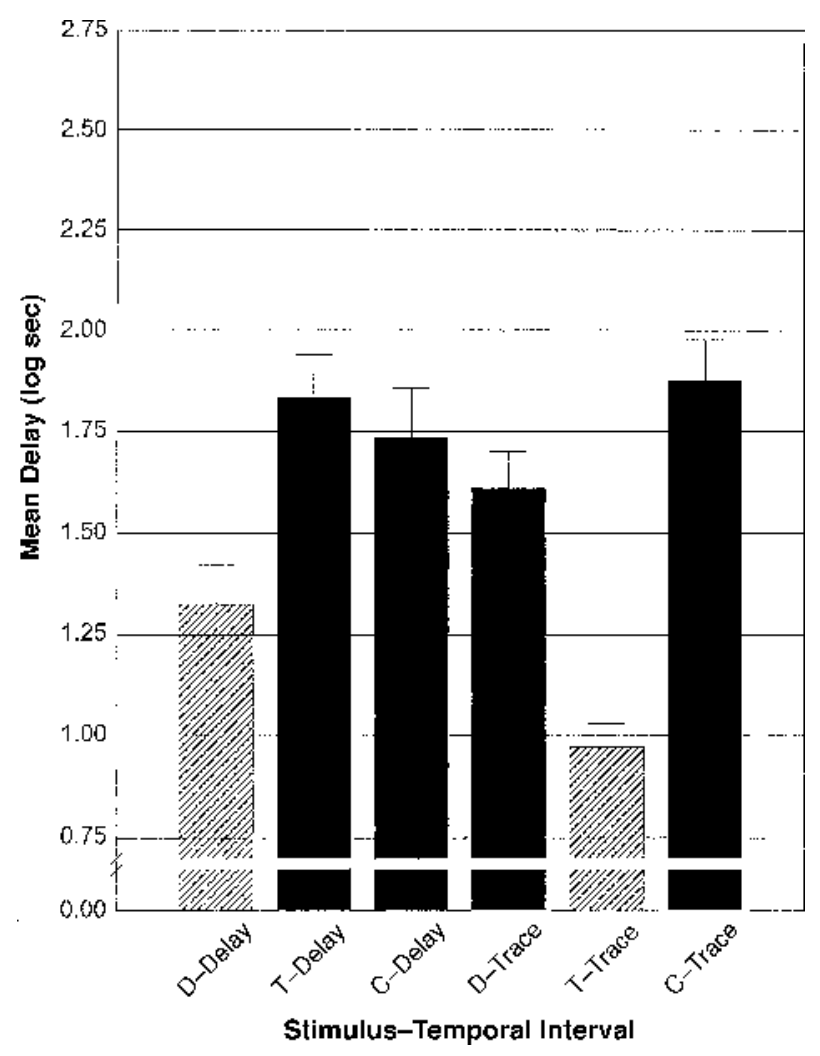

Figure 2. Experiment 2: retardation test. Treatment identification refers to stimulus trained during retardation test pairings (D2, T2, or C) and CS-US temporal interval (delay or trace). Bars depict mean times to complete five cumulative seconds of drinking in the presence of the test stimuli. Error bars denote the standard errors of the mean. Striped bars indicate groups in which maximal inhibition was expected. Higher scores indicate less retardation of behavioral control. See Table 2 for procedural details. 
$[F(1,64)=13.51, p<.001]$. Thus, retardation of stimulus control was observed in Group D-Delay, for which CS D2 was trained in both Phases 2 and 5 as a delay excitor. The second set of planned comparisons contrasted suppression by the animals that received trace conditioning of D2, T2, or C during retardation training. Analysis of these suppression scores revealed no difference in conditioned suppression between Groups D-Trace and C-Trace $[F(1,64)=3.91, p>.05]$ but less suppression in Group TTrace than in Group C-Trace $[F(1,64)=45.06, p<.001]$. In addition, Group T-Trace suppressed less than did Group D-Trace $[F(1,64)=22.43, p<.001]$. Thus, retardation was observed in Group T-Trace, for which CS T2 was trained as a trace excitor in Phases 2 and 5. Finally, a $2 \times 2$ ANOVA, with stimulus (D2 or T2) and temporal interval (delay or trace) as factors, was conducted on the suppression scores from Groups D-Delay, T-Delay, DTrace, and T-Trace. This analysis revealed no main effect of stimulus $(F<1)$ but a main effect of temporal interval $[F(1,43)=10.52, p<.01]$ and an interaction of these factors $[F(1,43)=41.45, p<.001]$.

The results of Experiment 2 indicate that a massively extinguished CS can pass a retardation test for conditioned inhibition. Moreover, inhibitory behavioral control was greatest when the CS-US temporal interval in force during initial excitatory training of the CS was maintained during retardation training. Changes in the CS-US temporal interval between these phases produced a loss of inhibition. That is, an extinguished delay CS was more retarded in reacquiring behavioral control when retrained as a delay CS, rather than as a trace CS, and an extinguished trace CS was more retarded in reacquiring behavioral control when retrained as a trace CS, rather than as a delay CS.

\section{GENERAL DISCUSSION}

The present findings indicate that, in our conditioned lick suppression preparation, a massively extinguishedCS can pass summation and retardation tests for conditioned inhibition. In addition, this form of inhibition appears to be influenced by temporal variables. In Experiment 1, an extinguished delay CS passed a negative summation test for conditioned inhibition when presented in compound with a delay transfer CS, but not with a trace transfer CS, and an extinguished trace CS passed a negative summation test for inhibition when tested with a trace transfer CS, but not with a delay transfer CS. Importantly, these results did not appear to be due solely to stimulus generalization decrement. Notably, some aspects of the results of Experiment 1 support the view that temporal variables influence the expression of behavior indicative of inhibition, whereas other aspects do not. For example, the extinguished trace CS (T2) produced reliable inhibition when compounded with the trace transfer CS (T1) and also produced substantial negative summation when compounded with the delay transfer CS (D1), and the extinguished delay and trace CSs (D2 and T2, respectively) produced nearly identical levels of negative summation when compounded with the delay transfer CS (D1). Thus, Experiment 1 failed to show strict temporal specificity (i.e., the temporal control was not all or none). Rather, greater inhibition was generally observed when the extinguished CS signaled US omission at the same temporal location as that at which the transfer excitor signaled US presentation, and this effect was weakened (in most instances) when the temporal expectancies were inconsistent. Experiment 2 showed that an extinguished delay CS was retarded in reacquiring behavioral control when the retardation pairings consisted of delay, but not trace, CS-US pairings and that an extinguished trace $\mathrm{CS}$ was retarded in reacquiring behavioral control when the retardation pairings consisted of trace, but not delay, CS-US pairings, results that fully support the temporal specificity of inhibition produced through extinction.

The finding that an extinguished CS can function as a conditioned inhibitor stands in contrast to several earlier reports that failed to observe inhibition produced through extinction. For example, Reberg (1972) found that an extinguished CS produced positive, rather than negative, summation when testing was conducted with a transfer excitor. However, Hendry (1982) found that this positive summation was gradually eliminated as the number of extinction trials was increased. Although other experiments have similarly failed to show inhibitory behavioral control by an extinguished stimulus (Konorski \& Szwejkowska, 1950, 1952; Macrae \& Kehoe, 1999), Bouton and his colleagues (Bouton, 1986; Bouton \& Swartzentruber, 1989) have found that, with sufficiently massive extinction, an extinguished stimulus is retarded in reacquisition of behavioral control, relative to a novel, but not to an equivalently exposed, stimulus. Thus, one potential factor that apparently determines when extinction will produce an inhibitor is the magnitude of extinction treatment. With relatively brief extinction experience, facilitated reacquisition and positive summation tend to be observed. But as the magnitude of extinction increases, positive summation wanes until negative summation occurs, and facilitated reacquisition wanes until retardation is observed.

Consistent with the above analysis, the present series of experiments provided massive extinction treatment $(1,000$ trials) and yielded both negative summation and retardation of behavioral control by an extinguished stimulus. These findings lend support to the observations of Calton et al. (1996). In their experiments, Calton et al. observed both negative summation and retardation of behavioral control by a massively extinguished flavor in a conditioned taste aversion preparation. Despite the numerous differences between their preparation and ours, similar patterns of results were observed. Together, these series of experiments provide converging evidence for the potential of an extinguished stimulus to function as a conditioned inhibitor.

A potential alternative explanation of the present results is that they do not actually reflect conditioned inhibition per se. Instead, they might be, at least in part, due to decreased attention to the extinguished CS, as was suggested by Pearce and Hall (1980; see also Aguado et al., 2001). 
According to Pearce and Hall, the associability of a CS decreases to the extent that the CS accurately predicted its most recent consequences. During the course of extinction, an inhibitory CS-US association is formed that reduces conditioned responding to the CS. As the strength of the inhibitory CS-US association approaches the strength of the excitatory CS-US association, expectation of the US decreases toward zero, consistent with extinction treatment, and consequently, the associability of the CS should itself approach zero. This decreased associability of the CS could potentially result in retarded reacquisition of behavioral control by the extinguished CS. As applied to Experiment 2, changes in the CS-US temporal relationship between initial excitatory training and retardation training should have been more surprising than was presenting the US at the same temporal location as that in initial excitatory training, thereby rapidly increasing the associability of the CS. Therefore, Pearce and Hall can account for the temporally specific retardation observed in Experiment 2 without assuming the existence of net inhibition for either CS.

Consistent with an attentional account of extinction, Aguado et al. (2001) found that an extinguished flavor (in a conditioned taste aversion preparation) was retarded in reacquiring behavioral control, relative to a novel CS, but not to an equivalently preexposed CS. More importantly, Aguado et al.'s Experiments 3 and 4 showed that an extinguished flavor CS passed a summation test for conditioned inhibition, but no more so than did an equivalently exposed neutral CS. That is, the appearance of negative summation was nothing more than stimulus generalization decrement. Thus, on the basis of their series of experiments, Aguado et al. concluded that decreased attention to an extinguished CS allows for the passing of a retardation test for conditioned inhibition and that stimulus generalization decrement is largely responsible for the apparent passing of a summation test for conditioned inhibition by an extinguished CS. However, there are a few potential problems with Aguado et al.'s procedure. In their Experiments 3 and 4 (in which the potential of an extinguished flavor to pass a summation test for conditioned inhibition was investigated), Aguado et al. failed to counterbalance the order of testing of the compound CS and the transfer excitor alone. That is, all the subjects received the compound test CS followed by the transfer excitor alone. This confound leads to the second test's being less informative, thereby limiting the conclusions that can be drawn from their summation test for conditioned inhibition. In addition, in their Experiment 4, Aguado et al. observed less negative summation by an extinguished CS than by a previously exposed neutral CS. One potential explanation for this result is that Aguado et al. interspersed extinction of the flavor CS with exposure to the neutral CS during the extinction treatment. This procedure resembles a differential inhibition procedure, which might have resulted in the acquisition of inhibition to the neutral CS (and, perhaps, protected the extinguished CS from extinction), thereby allowing the "neutral" $C S$ to pass a summation test for conditioned inhibition. Finally, Aguado et al. failed to equate exposure to the extinguished CS and the exposed neutral flavor (a consequence when the subject, rather than the experimenter, controls exposure to the CS). That is, during the course of their extinction treatment, the animals drank less of the conditioned flavor than of the neutral flavor (presumably owing to the acquired aversion), whereas in the present experiments, the experimenters controlled the timing of all stimulus presentations. Although the animals drank nearly equal amounts of the extinguished flavor and the neutral flavor by the end of the extinction treatment, such measures do not equate magnitude of exposure to the CS over the course of extinction treatment, which was equated in the present series of experiments.

Applied to the present series of experiments, an attentional explanation of extinction can account for only some aspects of our results. If extinction resulted in decreased attention to the extinguished CS, this decreased attention should have made it more difficult to observe negative summation in Experiment 1. That is, failure to attend to the putative inhibitor on a summation test should result in less negative summation (Rescorla, 1969). However, stimulus generalization decrement is another potential explanation for the apparent passing of a summation test for conditioned inhibition. To the end of ruling out such an account, Experiment 1 included test conditions in which the subjects received a previously exposed neutral CS in compound with the known excitors. Importantly, little negative summation was observed in these conditions, and the attenuation of fear in our test conditions, in which we expected to observe negative summation, generally exceeded any attenuation of fear produced by generalization decrement alone (e.g., Group T, Test Condition T1T2, relative to Group C, Test Condition T1C). Hence, stimulus generalization decrement appeared to have less of an impact on our results than on those of Aguado et al. (2001). Therefore, although an attentional explanation can account for the results of Experiment 2, it is unable to account for the results of Experiment 1. Despite the shortcomings of this alternative account, it remains possible that decreased attention to the CS did, in fact, play some role in the present experiments. For example, the inhibitory effects observed in the retardation test were greater than those observed in the summation test. This finding might reflect either decreased attention to the extinguished CS or, alternatively, greater sensitivity of retardation tests than of summation tests for conditioned inhibition.

\section{Extinction as Inhibition}

The possibility that extinction is the result of an inhibitory process (new learning), rather than of the weakening of an existing excitatory association, has been supported by numerous empirical findings, including spontaneous recovery of conditioned responding following extinction (Pavlov, 1927) and the renewal effect (Bouton \& Bolles, 1979). Bouton and Bolles found that following excitatory training in one context(A) and subsequent extinction treatment in a second context (B), conditioned responding was renewed (recovered) when testing was 
conducted in the training context (A) or in a third context (C), but not in the extinction context (B). These results suggest that extinction treatment does not result in the destruction of the original excitatory CS-US association. Rather, the loss of responding that results from extinction treatment appears to be the result of the formation of a context-specificinhibitory CS-US association (Bouton \& Nelson, 1994), which counters the initially established excitatory CS-US association. One way of viewing this context specificity of extinction is in terms of occasion setting by the context, in which the context enables an AND gate for the CS-US inhibitory association (in which the joint presence of the context and the CS is required for expression of extinction). When testing is conducted outside of the extinction context, the absence of the extinction context results in a failure of the inhibitory association to be activated. Thus, this simple model can readily anticipate the situations in which renewal will be observed.

Further evidence for the presence of inhibitory associations produced by extinction has been provided by Delamater (1996; see also Rescorla, 1996, 1997), who found that an extinguished CS enhanced the rate of instrumental responding of a response trained with the same, but not with a different, outcome as that with which the CS had been trained. These findings suggest that the Pavlovian stimulus-outcome ( $\mathrm{S}-\mathrm{O})$ association was preserved during extinction treatment and support an inhibitory interpretation of extinction. Delamater proposed the establishment of an inhibitory stimulus-response (S-R) association during the course of extinction. This inhibitory S-R association can explain both the loss of direct responding to the extinguished CS and the potential of the extinguished CS to transfer to instrumental responses (as a result of the preservation of the $\mathrm{S}-\mathrm{O}$ association). One potential account of the development of this inhibitory association is through the notion of overexpectation (Rescorla, 1997). When the CS is presented nonreinforced, the outcome representation by the CS is greater than can be supported by the absence of the outcome (or the presence of a second outcome). Rather than overexpectation resulting in a decrement in associative strength, as is assumed in the Rescorla-Wagner (1972) model, an inhibitory association may be formed between the stimulus and the response.

The application of an inhibitory S-R account (Rescorla, 1997) to the present series of experiments can account for some aspects of the present results. However, at least three fundamental problems exist when this account is applied to our results. First, traditional (nonreal-time) associative learning theory ignores the role of temporal information in associative learning. Therefore, to account for the present results, it must be assumed that animals encode the CS-US temporal interval as part of the acquired CS-US association, as suggested by the temporal coding hypothesis (Barnet et al., 1991; Matzel et al., 1988; Miller \& Barnet, 1993; Savastano \& Miller, 1998; see also Klopf, 1988; Sutton \& Barto, 1981). Second, the inhibitory S-R association formed as a result of overexpectation during extinction would also have to be temporally specific in order to account for the present data. If the expectation for the US during extinction peaks near the time at which the US was actually presented during training, it seems plausible that the strength of the activated inhibitory S-R association should be maximal at the peak activity of the excitatory S-R association. Third, and perhaps most problematic for the application of Rescorla's (1997) view of extinction to the present data, it is necessary to account for the observation that an extinguished CS can function as a net inhibitor. That is, if extinction of the CS resulted in a discrepancy between the expected US and the presented US, it might be expected that the inhibitory association should only be of sufficient strength to offset this discrepancy and, therefore, insufficient for the stimulus to function as a net inhibitor. For the extinguished CS to function as a net inhibitor, the inhibitory strength would have to be greater than the excitatory strength, which by Rescorla's (1997) account seems implausible.

What is needed here is an explanation as to why the inhibitory association appears to dominate over the excitatory association in the present series of experiments. One possibility is that the inhibitory $\mathrm{S}-\mathrm{R}$ association is more retrievable than the excitatory $S-R$ association at the time of testing. Such an account is provided by Bouton and Nelson (1994; Bouton, 1993). According to their model, an extinguished CS has two associations to the US, one excitatory and one inhibitory. Which association is more strongly retrieved at test is dependent on the context in which testing occurs. If the context is the same as that in which extinction treatment was administered, the inhibitory association will be more strongly retrieved, whereas if the physical or temporal context is changed at test, relative to that of extinction, the excitatory association is more apt to be retrieved. However, Denniston, Chang, and Miller (in press) found that massive extinction treatment (800 extinction trials following 8 acquisition trials), but not moderate extinction treatment ( 160 extinction trials following 8 acquisition trials), disrupts the renewal effect. That is, following acquisition training in one context (A), massive, but not moderate, extinction treatment in a different context (B) attenuated conditioned responding when testing was conducted either in a third context $(C)$ or in the context in which acquisition treatment had been provided (A). Denniston et al. suggested that massive extinction favors retrieval of the inhibitory association at the expense of the original excitatory association (i.e., the renewal effect reflects interference in memory retrieval, which can be reduced through massive extinction treatment, rather than occasion setting by context). Thus, massive extinction treatment might enhance the retrievability of the inhibitory association, thereby allowing for less renewal. Following moderate extinction treatment, empirical extinction is restricted to the extinction context because the context can facilitate retrieval of the inhibitory association only when subjects are in the presence of that context. When testing is conducted outside of the extinction context (following moderate extinction treatment), renewal is typically observed as a consequence of memory 
competition. Massive extinction might attenuate competition by the excitatory association by enhancing the retrievability of the inhibitory association, even in the absence of the extinction context.

As applied to the present series of experiments, the above account suggests that massive extinction treatment results in an inhibitory association that is more easily retrieved than the original excitatory association. This enhanced retrievability is likely due to both the magnitude of the extinction treatment provided and the presence of the extinction context during testing. That is, massive extinction treatment and all phases of training occurring in the same physical context might facilitate retrieval of the inhibitory association at the expense of the excitatory association, thereby allowing an extinguished CS to pass both summation and retardation tests for conditioned inhibition. Importantly, this account does not posit that extinction results in net inhibition; rather, a massive extinction treatment gives rise merely to the appearance of net inhibition as a consequence of differential memory retrieval. Combined with the assumption of temporal coding (see above), this account can readily explain the results of the present series of experiments.

On the basis of the present results, it appears that the extinguished CS effectively became a signal for US omission (or at least, decreases in US expectation) at a specific temporal location. Although the exact mechanism for establishing this inhibitory expectation remains elusive, several prior accounts of extinction can be ruled out. Clearly, the initial excitatory association is not abolished, as is posited by many contemporary associative theories (e.g., Rescorla $\&$ Wagner, 1972) and connectionist models (e.g., Buhusi \& Schmajuk, 1999; Desmond \& Moore, 1988; Sutton \& Barto, 1981). Second, the original CS-US association must be retrievable during the course of extinction in order for the inhibitory association to acquire temporal information. That is, if extinction prevents retrieval of the excitatory association (e.g., Bouton, 1993), how does an extinguished CS display temporal specificity? Clearly, some aspect of the initial CS-US association must be retrievable during the course of extinction and/or at test.

As was previously discussed, an account of the present results that emphasizes the acquisition of an inhibitory $\mathrm{S}-\mathrm{R}$ association during the course of extinction has considerable explanatory power. To review, initial excitatory training might establish both $\mathrm{S}-\mathrm{O}$ and $\mathrm{S}-\mathrm{R}$ associations, in which the $\mathrm{S}-\mathrm{R}$ association exerts temporal control of responding to the CS. Then, during the course of extinction treatment, an inhibitory $\mathrm{S}-\mathrm{R}$ association that is maximally inhibitory at the temporal peak of the excitatory $\mathrm{S}-\mathrm{R}$ association is established. This inhibitory $\mathrm{S}-\mathrm{R}$ association merely reduces responding controlled by the excitatory $\mathrm{S}-\mathrm{R}$ association, leaving the $\mathrm{S}-\mathrm{O}$ association intact and fully retrievable (allowing for transfer to instrumental responses; e.g., Delamater, 1996). Finally, differential memory retrieval, influenced by both the magnitude of the extinction treatment and the presence of the extinction context (thereby maximizing interference of the inhibitory
S-R association with the excitatory S-R association), could readily explain whether inhibitory or excitatory behavioral control by the CS will be observed. In summary, what is clearly needed is an account of extinction that provides for a temporally precise inhibitory process. Such an account must include mechanisms for both temporal coding (e.g., the temporal coding hypothesis) and the acquisition of behavioral inhibition as a result of nonreinforcement. The inhibitory S-R account described above represents a starting point for the development of such a model.

\section{REFERENCES}

Aguado, L., De Brugada, I., \& Hall, G. (2001). Tests for inhibitionafter extinction of a conditioned stimulus in the flavour aversion procedure. Quarterly Journal of Experimental Psychology, 54B, 201-218.

Barnet, R. C., Arnold, H. M., \& Miller, R. R. (1991). Simultaneous conditioning demonstrated in second-order conditioning: Evidence for similar associative structure in forward and simultaneous conditioning. Learning \& Motivation, 22, 253-268.

Barnet, R. C., \& Miller, R. R. (1996). Temporal encoding as a determinant of inhibitory control. Learning \& Motivation, 27, 73-91.

Bouton, M. E. (1986). Slow reacquisition following the extinction of conditioned responding. Learning \& Motivation, 17, 1-15.

Bouton, M. E. (1993). Context, time, and memory retrieval in the interference paradigms of Pavlovian learning. Psychological Bulletin, 114, 80-99.

Bouton, M. E., \& Bolles, R. C. (1979). Contextual control of the extinction of conditioned fear. Learning \& Motivation, 10, 455-466.

Bouton, M. E., \& Nelson, J. B. (1994). Context-specificity of target versus feature inhibition in a feature-negative discrimination. Journal of Experimental Psychology: Animal Behavior Processes, 20, 51-65.

Bouton, M. E., \& Swartzentruber, D. E. (1989). Slow reacquisition following extinction: Context, encoding, and retrieval mechanisms. Journal of Experimental Psychology: Animal Behavior Processes, 15, 43-53.

Buhusi, C. V., \& Schmajuk, N. A. (1999). Timing in simple conditioning and occasion setting: A neural network approach. Behavioural Processes, 45, 33-57.

Burger, D. C., Denniston, J. C., \& Miller, R R. (2001). Temporal coding in conditioned inhibition: Retardation tests. Animal Learning \& Behavior, 29, 281-290.

Calton, J. L., Mitchell, K. G., \& Schachtman, T. R. (1996). Conditioned inhibition produced by extinction of a conditioned stimulus. Learning \& Motivation, 27, 335-361.

Delamater, A. R. (1996). Effects of several extinction treatments upon the integrity of Pavlovian stimulus-outcome associations. Animal Learning \& Behavior, 24, 437-449.

Denniston, J. C., Blaisdell, A. P., \& Miller, R. R. (1998). Temporal coding affects transfer of serial and simultaneous inhibitors. Animal Learning \& Behavior, 26, 336-350.

Denniston, J. C., Chang, R., \& Miller, R. R. (in press). Massive extinction prevents the renewal effect. Learning \& Motivation.

Denniston, J. C., Cole, R. P., \& Miller, R. R. (1998). The role of temporal variables in the transfer of conditioned inhibition. Journal of Experimental Psychology: Animal Behavior Processes, 24, 200-214.

Desmond, J. E. \& Moore, J. W. (1988). Adaptive timing in neural networks: The conditioned response. Biological Cybernetics, 58, 405 415.

Friedman, B. X., Blaisdell, A. P., Escobar, M., \& Miller, R. R. (1998). Comparator mechanisms and conditioned inhibition: Conditioned stimulus preexposure disrupts Pavlovian conditioned inhibition but not explicitly unpaired inhibition. Journal of Experimental Psychology: Animal Behavior Processes, 24, 453-466.

Hart, J. A., Bourne, M. J., \& Schachtman, T. R. (1995). Slow reacquisition of a conditioned taste aversion. Animal Learning \& Behavior, 23, 297-303.

HeArst, E. (1972). Some persistent problems in the analysis of condi- 
tioned inhibition. In R. A. Boakes \& M. S. Halliday (Eds.), Inhibition and learning (pp. 5-39). London: Academic Press.

HENDRY, J. S. (1982). Summation of undetected excitation following extinction of the CER. Animal Learning \& Behavior, 10, 476-482.

HonIG, W. K. (1981). Working memory and the temporal map. In N. E. Spear \& R. R. Miller (Eds.), Information processing in animals: Memory mechanisms (pp. 167-197). Hillsdale, NJ: Erlbaum.

KLOPF, A. H. (1988). A neuronal model of classical conditioning. Psychobiology, 16, 85-125.

KonORSKI, J. (1948). Conditioned reflexes and neural organization. Cambridge: Cambridge University Press.

Konorski, J., \& SzWEJKowska, G. (1950). Chronic extinction and restoration of conditioned reflexes: I. Extinction against the excitatory background. Acta Biologiae Experimentalis, 15, 155-170.

Konorski, J., \& SzWeJkowska, G. (1952). Chronic extinction and restoration of conditioned reflexes: III. Defensive motor reflexes. Acta Biologiae Experimentalis, 16, 91-94.

LoLordo, V. M., \& Rescorla, R. A. (1966). Protection of the feareliciting capacity of a stimulus from extinction. Acta Biologiae Experimentalis, 26, 251-258.

Macrae, M., \& Kehoe, E. J. (1999). Savings after extinction in conditioning of the rabbit's nictitating membrane response. Psychobiology, 27, 85-94.

Matzel, L. D., Held, F. P., \& Miller, R. R. (1988). Reexamination of simultaneous and backward conditioning: Implications for contiguity theory. Learning \& Motivation, 19, 317-344.

Melton, A. W., \& Irwin, J. M. (1940). The influence of degree of interpolated learning on retroactive inhibition and the overt transfer of specif ic responses. American Journal of Psychology, 53, 173-203.

Miller, R. R., \& BARNet, R. C. (1993). The role of time in elementary associations. Current Directions in Psychological Science, 2, 106-111.

Miller, R. R., \& MATZEL, L. D. (1988). The comparator hypothesis: A response rule for the expression of associations. In G. H. Bower (Ed.), The psychology of learning and motivation (Vol. 22, pp. 51-92). San Diego: Academic Press.

Pavlov, I. P. (1927). Conditioned reflexes (G. V. Anrep, Trans.). London: Oxford University Press.

Pearce, J. M., \& Hall, G. (1980). A model for Pavlovian conditioning: Variations in the effectiveness of conditioned but not unconditioned stimuli. Psychological Review, 87, 332-352.

Postman, L., \& Stark, K. (1969). Role of response availability in transfer and interference. Journal of Experimental Psychology, 79, 168-177.

REBERG, D. (1972). Compound tests for excitation in early acquisition and after prolonged extinction of conditioned suppression. Learning \& Motivation, 3, 246-258.

Rescorla, R. A. (1969). Pavlovian conditioned inhibition. Psychological Bulletin, 72, 77-94.
Rescorla, R. A. (1996). Preservation of Pavlovian associations through extinction. Quarterly Journal of Experimental Psychology, 49B, 245258.

RESCORLA, R. A. (1997). Spontaneous recovery after Pavlovian conditioning with multiple outcomes. Animal Learning \& Behavior, 25, 99 107.

Rescorla, R. A., \& Furrow, D. R. (1977). Stimulus similarity as a determinant of Pavlovian conditioning. Journal of Experimental Psychology: Animal Behavior Processes, 3, 203-215.

Rescorla, R. A., \& Wagner, A. R. (1972). A theory of Pavlovian conditioning: Variations in the effectiveness of reinforcement and nonreinforcement. In A. H. Black \& W. F. Prokasy (Eds.), Classical conditioning II: Current research and theory (pp. 64-99). New York: Appleton-Century-Crofts.

Savastano, J. I., \& Miller, R. R. (1998). Time as content in Pavlovian conditioning. Behavioural Processes, 44, 147-162.

Schachtman, T. R., Threlkeld, R, \& Meyer, K. (2000). Retention of conditioned inhibition produced by extinction. Learning \& Motivation, 31, 283-300.

Sergeyev, B. F. (1961). On the localization of inhibition in the extinction of conditioned reflexes to chain stimuli. Pavlov Journal of Higher Nervous Activity, 11, 695-700.

Sutton, R. S., \& Barto, A. G. (1981). Toward a modern theory of adaptive networks: Expectation and prediction. Psychological Review, 88, 135-170.

TCHILINGARYAN, L. I. (1963). Changes in excitability of the motor area of the cerebral cortex during extinction of a conditioned reflex elaborated to direct electric stimulation of that area. In E. Gutman \& P. Nhik (Eds.), Central and peripheral mechanisms of motor functions (pp. 167-175) Prague: Publishing House of the Czechoslovak Academy of Sciences.

WAGNER, A. R. (1981). SOP: A model of automatic memory processing in animal behavior. In N. E. Spear \& R. R. Miller (Eds.), Information processing in animals: Memory mechanisms (pp. 5-47). Hillsdale, NJ: Erlbaum.

Wagner, A. R., Mazur, J. E., Donegan, N. H., \& Pfautz, P. L. (1980). Evaluation of blocking and conditioned inhibition to a CS signaling a decrease in US intensity. Journal of Experimental Psychology: Animal Behavior Processes, 6, 376-385.

Williams, D. A., \& Overmier, J. B. (1988). Some types of conditioned inhibitors carry collateral excitatory associations. Learning \& Motivation, 19, 345-368.

(Manuscript received January 5, 2002; revision accepted for publication July 15,2002 .) 